\title{
RUSSIAN CONFERENCE ON COLD TRANSMUTATION OF NUCLEI (1993-2017)
}

\section{Yuri N. Bazhutov}

Scientific-research centre for engineering and physical problems "Erzion"

Moscow 109451, Russian Federation

erzion@mail.ru

Abstract. The information about the Russian conferences on cold transmutation of nuclei of chemical elements and ball lightning (RCCTN\&BL) is presented, which occurring in the Krasnodar coast of Black sea (Abrau-Dyurso, Sochi, Lazorevskoe, Dagomys, Loo, Krinitsa), annually since 1993.

Keywords: coordination council, conference, cold transmutation of nuclei of chemical elements, ball lightning

UDC 061.053, 539.172

References -4

Received 20.06.2017

RENSIT, 2017, 9(1):113-115

DOI: $10.17725 /$ rensit.2017.09.113

\section{Contents}

1. INTRODUCTION (113)

2. Organizing COMMitTEe OF 24TH RCCTN\&BL-2017 (114)

3. The main directions of Research (115)

4. Organizational matters (115)

5. Conclusion (115)

REFERENCES (115)

\section{INTRODUCTION}

From the first steps of nuclear physics by the its low-energy direction is not lucky: E. Rutherford, captivated by prospects development nuclear power, declared as the incorrect the first works on nuclear reactions at low energy [1], and they went underground. However, after the publication in 1989 M. Fleischmann and S. Pons (USA) in Journal of Electroanalytical Chemistry [2] and their interview at a press conference on March 23, 1989, published to the newspaper "Financial Times" in which they stated that it is possible to create energy source of the industrial scale based on the fusion of nuclei of heavy hydrogen at room temperature, studies of low-energy nuclear reactions has been obtain widely developed in many laboratories of the world. In countries such as USA, Japan, Italy, China and other, these studies are funded by the state programs and the largest firms (Toyota, Honda, Mitsubishi, Fiat, etc).

Since 1990, annual International Conference on Cold Fusion (ICCF, 2007 - International Conference on Condensed Matter Nuclear Science) in the United States, Canada, Japan, Italy, France, China, Korea,
India and other countries is conducted. There are an electronic journal http://newenergytimes.com, sites (one of the largest - www.lenr-forum.com) on lowenergy nuclear reactions [3].

In Russia, these studies became involved Kurchatov Institute of atomic energy (Moscow), JINR (Dubna) and other institutes of Academy of Sciences of the USSR, universities, Scientificresearch institute scientific-production association "Luch" (Podolsk) and other research institutes of our country. In 1991, all-Union conference "Cold nuclear fusion" at JINR-Dubna - MSU-Moscow under the chairmanship of the academician of the AN USSR Y.M. Kolotyrkin is conducted. In 1992, the UFN publishes a review of Dr Sci Phys\&Math V.A. Tsarev (Lebedev Physical Institute). In 1993 the Coordinating board on anomalous nuclear phenomena in condensed matter, the Chairman - Dr Sci Chem, academician of the AN USSR Baraboshkin A.N. (IECh UrF USSR Academy of Sciences, Yekaterinburg) is organized. This Board provided the two-year state grant for these studies. The First Russian conference on cold nuclear fusion in Abrau-Dyurso, 1993 was conducted. In 1994, in Sochi the 2nd conference was held already under the name "Cold fusion and transmutation of nuclei". In 1996, after the death of academicians Baraboshkin A.N. and Kolotyrkin Y.M. the Interdepartmental coordination board on the problem of "Cold fusion" under the Vice-President of RAS, Dr Sci Chem O.M. Nefedov, Chairman of the Board Dr Sci Chem, academician V.E. Kazarinov (Frumkin IPCE RAS) is organized. 5th Russian conference in 
Dagomys (1997) is conducted under the name "Cold transmutation of nuclei of chemical elements". In 2004, the Interdepartmental coordination Board on the problem of "Cold transmutation of nuclei" under the Russian physical society is organized (until 2012). Since the tenth conference (2002) it is called Russian conference on cold transmutation of nuclei of chemical elements and ball lightning (RCCTN\&BL). In 2007, in Dagomys (Sochi) the 13th International Conference on Cold Transmutation of Nuclei of chemical elements (ICCF-13) was conducted. In September 2017 in Sochi will be held the next annual 24th RCCTN\&BL.

Since 2017, the Coordinating Board on the problem of "Cold transmutation of nuclei" (CB CTN) was registered in the Russian Academy of Natural Sciences (RANS) and operates in the following composition.

1. Chairman CB CTN - Henri Amvrosievich Rukhadze, Dr. Sci Phys\&Math, Professor, academician of RANS, chief researcher of Prokhorov GPI RAS, Moscow, Russia.

\section{Co-Chairmans CB CTN:}

2. Victor Victorovich Apollonov, Dr Sci Phys\&Math, Professor, academician of RANS, Prokhorov GPI RAS, Moscow, Russia;

3. Yuri Nikolaevich Bazhutov, PhD Phys\&Math, senior researcher, corresponding member of RANS, Scientific-research center for engineering and physical problems "Erzion" (SRC EPP "Erzion"), Moscow.

\section{Vice-Chairman CB CTN:}

4. Runar Nikolaevich Kuzmin, Dr. Sci Phys\&Math, Professor, Lomonosov Moscow State University, Physical Faculty;

5. Nikolay Vladimirovich Samsonenko, $\mathrm{PhD}$ Phys\&Math., corresponding member of RANS, associate Professor of the Russian University of friendship of peoples (RUFP).

6. Scientific Secretary - Albina Ivanovna Gerasimova, PhD Chem, associate Professor, corresponding member of RANS, SRC EPP "Erzion", Moscow.

Members of the coordinating Board of the cold nuclear transmutation:

7. Stepan Nikolaevich Andreev, Dr Sci Phys\&Math, Prokhorov GPI RAS, Moscow;
8. Dmitry Sergeevich Baranov, PhD Phys\&Math, Joint Institute for High Temperatures of the Russian Academy of Sciences (JIHT RAS)

9. Vsevolod Valerievich Botvinovsky, PhD Phys\&Math, senior researcher, corresponding member of RANS, Novosibirsk plant of industrial instrumentation (NPII), Novosibirsk, Russia;

10. Aleksandr Nikolaevich Vlasov, Dr Sci Phys\&Math, Professor, corresponding member of Academy of electrotechnical Sciences of the Russian Federation, Ryazan state radio engineering University (RSREU), Ryazan;

11. Sergey Mikhaylovich Godin, LLC Lokterm, Moscow;

12. Igor Vitalievich Goryachev, Dr Sci Techn, Professor, Moscow;

13. Valery Nikolaevich Zatelepin, PhD Techn, LLC "Inlis", Moscow;

14. Pyotr Vasilyevich Zakharov, PhD Phys\&Math, SRC EPP "Erzion", Moscow;

15. Mikhail Yakovlevich Ivanov, Dr Sci Phys\&Math, Professor, corresponding member of RANS, Central institute of aviation motors (CIAM), Moscow;

16. Vitaliy Alekseevich Kirkinsky, Dr Sci GeolMin, Institute of Geology and Mineralogy SB RAS, Novosibirsk;

17. Anatoly Ivanovich Klimov, Dr. Sci Phys\&Math, academician of RANS, Joint Institute for High Temperatures RAS, Moscow;

18. Alla Aleksandrovna Kornilova, PhD Phys\&Math, Lomonosov Moscow State University, Moscow;

19. Alexei Ivanovich Laptukhov, PhD Phys\&Math, associate Professor, Pushkov Institute of Terrestrial Magnetism, Ionosphere and Radio Wave Propagation of RAS (IZMIRAN), Troitsk, Moscow;

20. Alexander Georgievich Parkhomov, PhD Phys\&Math, corresponding member of RANS, Experimental-Design Laboratory "K. I. T.", Moscow; 21. Boris Ustinovich Rodionov, Dr. Sci Phys\&Math, Professor, academician of RAEN, Institute of content and methods of education Russian Academy of education, Moscow;

22. Alexey Sergeevich Rusetsky, PhD Phys\&Math, Lebedev Physical Institute of RAS, Moscow;

23. Irina Borisovna Savvateeva, PhD Techn, Scientific Research Institute "Luch", Podolsk, Moscow region; 24. Sergey Alekseevich Tsvetkov, PhD Techn, pensioner, Ekaterinburg; 
25. Ivan Petrovich Chernov, Dr. Sci Phys\&Math, Professor, Tomsk Polytechnic University, Tomsk;

\section{ORGANIZING COMMITTEE OF 24th RCCTN\&BL-2017}

Bazhutov Yu.N. - Chairman, SRC EPP "Erzion";

Bychkov V.L. - Vice-Chairman, Lomonosov Moscow

State University;

Samsonenko N.V. - Deputy Chairman, RUFP;

Gerasimova A.I. - Secretary, SRC EPP "Erzion";

Prosvirnov A. A. - editor of the Russian web site, JSC VNIIAES (Moscow);

Shestopalov A.V. - editor of video web site, Melnikov

Research Institute of Comprehensive Exploitation of Mineral Resources RAS, Moscow.

Members of the organizing Committee:

Klimov A.I. - JIHT RAS, Moscow;

Kornilova A.A. - Lomonosov Moscow State

University;

Parkhomov A.G. - EDL "K. I. T.";

Famina N. V. - STU MADI.

\section{THE MAIN DIRECTIONS OF RESEARCHES}

1. Physics of cold transmutation of nuclei of chemical elements.

2. Experimental studies and theoretical models of cold nuclear transmutation.

3. Environmental issues associated with the phenomenon of cold transmutation of nuclei.

4. Physics of ball lightning. Pilot studies. Reviews and theoretical models.

\section{ORGANIZATIONAL ISSUES}

The conference, usually is conducted in autumn, in September, in Sochi, Dagomys settlement, Krasnodar area, boarding house "Olympic-Dagomys" [3].

The conference gathers for weekly your from 20 to 50 participants from 20-30 different scientific organizations of Russia - Moscow and the Moscow region, St-Petersburg, Novosibirsk, Armavir, Volgograd, Rostov-on-Don, Krasnodar, Sochi etc. Are presenting about 40 reports - overview, experimental and theoretical. Including up to a quarter of the reports on the problem of ball lightning.

Its regular participants are foreign researchers from the USA, Japan, Italy, China, France, Belgium and other countries.
The conference takes place at the expense of the organizing Committee and authors of articles. Episodically the Russian and foreign firms involve in the sponsorship.

The conference proceedings are published at the expense of the organizing Committee of RCCTN\&BL and articles authors. The conference proceedings are indexed in Russian Science Citation Index (RSCI) and registered in Book Chamber of the Russian Federation.

The conference informs about its activities the Nuclear Society of Russia, Mendeleev Russian Chemical Society, Lomonosov Moscow State University, the Russian University of Friendship of Peoples.

\section{CONCLUSION}

The systematic conduct of the conference, the activity of its participants, saturation of an annual programme attested to the relevance of the existence of the conference as a working platform, promoting the development of researches the problem of cold transmutation of nuclei of chemical elements.

\section{REFERENCES}

1. Rutherford E. Identification of a missing element. Nature, London, 1922, 109:781.

2. Fleishmann $\mathrm{M}$, Pons S, Hawkins $\mathrm{M}$. Electrochemically induced nuclear fusion of deuterium. J. Electroanal. Chem., 1989, 261:301-308.

3. Ehrlich G.V., Andreev S.N. The history of nuclear physics in the mirror of alchemy: from the beginning of the twentieth century to the sensational discoveries of present days. Moscow, LENAND Publ., 2017, 232 p.

4. The problems of cold transmutation of nuclei of chemical elements and ball lightning. Materials of 23nd Russian conference on RCCTN\&BL. June 2016, Dagomys, Sochi, 2016, 310 s. 